\title{
Reply on Comments on the paper "Clinical characteristics and treatment of pars planitis: an adalimumab experience" by Ozdemir et al
}

\author{
Huseyin Baran Ozdemir ${ }^{1}$ (D) . Pinar Cakar Ozdal ${ }^{2}$ (D) \\ Received: 12 December 2021 / Revised: 12 December 2021 / Accepted: 14 December 2021 / Published online: 28 January 2022 \\ (c) The Author(s), under exclusive licence to Springer-Verlag GmbH Germany, part of Springer Nature 2021
}

\section{Dear Editor,}

We thank Dr. Francois Pepin and Dr. Rachael L Niederer for the valuable comments on our article "Clinical characteristics and treatment of pars planitis: an adalimumab experience" [1]. They wanted to emphasize two important points in patients with intermediate uveitis, which we also agree with. First, they indicated that demyelinating diseases such as multiple sclerosis should be ruled out with radiologic examination, especially to distinguish neurologically asymptomatic patients. We agree that demyelinating diseases should be excluded in patients with pars planitis. In addition, screening for demyelinating diseases should be done at certain intervals during the follow-up of the patients. In our clinical practice, we perform routine cranial MRI examinations during systemic evaluation in patients diagnosed with intermediate uveitis, and we repeat the MRI examination every 2 years in these patients. Healthcare system in Turkey provides fast and easy MRI examination, so demyelinating diseases were excluded with cranial MRI in all our patients in our cohort. Furthermore, in pediatric patients with pars planitis, an approval by a neurologist is mandatory for the use of anti-TNF agents. Second, they asked how we screen for sarcoidosis. We agree that the diagnosis of sarcoidosis is very challenging. In our clinical practice, we screen for sarcoidosis, tuberculosis, and syphilis in all intermediate uveitis patients. We do not perform tuberculosis and sarcoidosis screening ourselves, and we refer the patient to a pulmonologist. These patients are evaluated with a complete systemic examination, blood tests, and lung X-ray, and further examinations such as lung CT or biopsy are performed for patients with suspicious findings.

\section{Declarations}

Conflict of interest Huseyin Baran Ozdemir has no conflicts of interest. Pinar Cakar Ozdal has received consultancy and lecture fees from AbbVie, Turkey; lecture fees from Novartis, Turkey; and lecture fees from Bayer, Turkey. The authors have no other relevant affiliations or financial involvement with any organization or entity with a financial interest in or financial conflict with the subject matter or materials discussed in the manuscript apart from those disclosed.

\section{Reference}

1. Ozdemir HB, Ozdal PC (2021) Clinical characteristics and treatment of pars planitis: an adalimumab experience. Graefes Arch Clin Exp Ophthalmol. https://doi.org/10.1007/ s00417-021-05398-4

Publisher's Note Springer Nature remains neutral with regard to jurisdictional claims in published maps and institutional affiliations.
Huseyin Baran Ozdemir

huseyinbaranozdemir@gazi.edu.tr

1 Department of Ophthalmology, Gazi University School of Medicine, Ankara, Turkey

2 Department of Ophthalmology, Ulucanlar Eye Training and Research Hospital, University of Health Sciences, Ankara, Turkey 